\title{
CARACTERIZAÇÃO FÍSICO-QUÍMICA DOS FLUIDOS ASSOCIADOS AOS VEIOS DE QUARTZO AURÍFEROS DE COSTA SENA - MG
}

\author{
LUIZ H. RONCHI*, GASTON GIULIANI**, CLAIRE BENY**** ANTONIO C.C. FOGAÇA
}

\begin{abstract}
PHYSICO-CHEMICAL EVOLUTION OF THE FLUIDS ASSOCIATED TO THE COSTA SENA GOLD QUARTZ VEINS (MG - BRAZIL). The fluid inclusion study of free-gold-bearing quartz veins from Costa Sena gold occurences, Minas Gerais, shows that both aquo-carbonic $\left(\mathrm{C}_{2}\right.$ and $\left.\mathrm{C}_{1}\right)$ and the aqueous (L) fluids were present during the mineralizing event The early stage $\mathrm{C}_{2}$ fluid (of composition 82,2 mole $\% \mathrm{H}_{2} \mathrm{O} ; 16$ mole $\% \mathrm{CO}_{\mathrm{Z}} ; 1,8$ mole $\% \mathrm{NaCl}$ ) was progressively diluted, at around $350^{\circ} \mathrm{C}$ and $2,0-2,5 \mathrm{kbar}$, by an $\mathrm{H}_{2} \mathrm{O}$ fluid $(\mathrm{L})$ with and increase of density (fluid $\mathrm{C}_{1}$ of composition 94 mole $\% \mathrm{H}_{2} \mathrm{O} ; 3,8$ mole $\% \mathrm{CO}_{2} ; 2,2$ mole $\% \mathrm{NaCl}$ ). The $\mathrm{fO}_{2}$ conditions of the early aquo-carbonic fluid based on the absence of $\mathrm{CH}_{4}, \mathrm{H}_{2} \mathrm{~S}, \mathrm{~N}_{2}$, the absence of sulphides and the stability of hematite in the veins, is close to the hematite - magnetite buffer. The role of both the aquo-carbonic and aquous fluids in the transport and precipitation of gold is discussed: deposition of native gold can be ascreibed, at a relatively constant fO2, to the destabilization of $\mathrm{AuCl}_{2}$ - complex in the circulating fluids, as a result of the mixing of two defined fluid types.
\end{abstract}

Keywords: Fluid inclusions, quartz veins, gold, Brazil, Raman microprobe, micro-thermometry.

\begin{abstract}
RESUMO O estudo das inclusões fluidas dos veios de quartzo auríferos em Costa Sena, MG, demonstrou que fluidos aquo-carbônicos $\left(\mathrm{C}_{2}\right.$ e $\left.\mathrm{C}_{1}\right)$ e aquosos estavam presentes durante o evento mineralizante. $\mathrm{O}$ fluido precoce $\mathrm{C}_{2}$ (de composição 82,2 mole $\% \mathrm{H}_{2} \mathrm{O} ; 16$ mole $\% \mathrm{CO}_{2} ; 1,8$ mole $\% \mathrm{NaCl}$ ) foi progressivamente diluído, em aproximadamente $350^{\circ} \mathrm{C}$ e 2,2-2,5 kbar, por um fluido aquoso (L), com um aumento de densidade produzindo o fluido $\mathrm{C}_{1}$ (de composição 94 mole $\% \mathrm{H}_{2} \mathrm{O} ; 3,8$ mole $\% \mathrm{CO}_{2} ; 2,2 \mathrm{~mole} \% \mathrm{NaCl}$ ). A fO $\mathrm{f}_{2}$. do fluido aquo-carbônico, estimada a partir da ausência de $\mathrm{CH} 4, \mathrm{H}_{2} \mathrm{~S}, \mathrm{~N}_{2}$ e pela ausência de sulfetos nos veios, é próxima às condições do tampão (buffer) hematita-magnetita. A deposição do ouro é devida à desestabilização do complexo $\mathrm{AuCl}_{2}$ - em resultado do processo de diluição, conduzindo a um aumento do $\mathrm{pH}$ dos fluidos em condições de fugacidade de oxigênio relativamente constantes.
\end{abstract}

Palavras-chaves: Inclusões fluidas, veios de quartzo, ouro, Brasil, espectrometria Raman, microtermometria.

INTRODUÇÃO As ocorrências auríferas de Costa Sena, situadas a $200 \mathrm{~km}$ ao norte de Belo Horizonte (Fig. 1), estão encaixadas numa seqüência metavulcanossedimentar que pertence ao Supergrupo Rio Paraúna. Os trabalhos geológicos desenvolvidos na área de Costa Sena mostraram que as várias fácies litológicas podem ser agrupadas nas seguintes divisões estratigráficas: Complexo Granítico e Supergrupo Serra da Paraúna, ambos de idade arqueana e Supergrupo Espinhaço, pertencente ao Proterozóico Inferior (Fig. 1). Entretanto, Inda et al. (1984) apresentam hipóteses diferentes em relação à estratigrafia regional.

O Complexo Granítico (também chamado Granito de Gouveia), que apresenta amplas variações petrográficas, é predominantemente composto por um granito porfiróide com grandes fenocristais de feldspato (microclínio) orientados em matriz hipiodiomórfica granular. Alguns autores, como Pflug \& Carvalho (1964), o consideram como de origem magmática e intrusiva, ao passo que outros (Hoffman 1980 in Schöll 1980) o caracterizaram como granito de anatexia distinto em formação de idade dos micaxistos da região. Inda et al. (1984) referem-se a existência de evidências de metassomatismo potássico, que teria originado os pórfiros de feldspato após a formação da matriz da rocha, conforme sugerido por Pflug \& Carvalho (1964). Estruturalmente, este complexo granítico apresenta zonas de cisalhamento complexo (e possivelmente desenvolvidos em um estágio dúctil), de direção NNW, que provocaram a formação de protomilonitos e filonitos.

O filonito Rio Paraúna é composto por xistos verdes, mica-xistos com quantidades variáveis de quartzo e cianita, e pequenas camadas de itabiritos e quartzitos. Estruturalmente, possui forma de quilha com direção NW, bordejada pelos granitóides e metassedimentos mais recentes e com um padrão de dobramento isoclinal assimétrico em pequena e grande escala. Pode ainda, preservando parcialmente suas dobras abertas, incluir uma série de falhas inversas, com vergência W, associadas com falhas de deslocamento, na porção leste da área.

No Supergrupo Espinhaço, distinguem-se duas unidades metassedimentares pertencentes à Formação Sopa Brumadinho, a saber: uma, inferior, denominada nível $\mathrm{E}$, composta por quartzitos e metaconglomerados com ocorrências locais de hematita filitos de origem vulcânica, e membro Campo Sampaio, caracterizado por uma sucessão rítmica de filitos e quartzitos micáceos.

Todas estas unidades sofreram intrusões de diques e stocks metabásicos de idade pós-Espinhaço.

As pequenas ocorrências de ouro são encontradas geralmente associadas a veios de quartzo em zonas de cisalhamento do Supergrupo Rio Paraúna (Serra do Espinhaço Meridional). O objetivo deste trabalho consiste em investigar a natureza das soluções que transportaram o ouro e caracterizar os processos físico-químicos responsáveis pela sua precipitação, por meio de estudos de inclusões fluidas de ganga de quartzo das três ocorrências auríferas de Costa Sena.

AS MINERALIZAÇÕES AURÍFERAS DE COSTA SENA A única mina de ouro da região - conhecida como mina do Periquito e distante $4 \mathrm{~km}$ a WS W do povoado de Costa Sena - situa-se em terrenos constituídos por xistos do Supergrupo Rio Paraúna (Fig. 1). Atualmente paralizada, ela apre-

\footnotetext{
* Laboratório D'Etude des Ressources et Matériaux Minéraux, Ecole Supérieure de UEnergie et des Matériaux, Université d'Orléans, Boêite Postale 6747,45067 Orleans Cedex 2, France

** Departamento de Geoquímica e Recursos Minerais, Instituto de Geociências, Universidade de Brasília/ORSTOM, CEP 70910-900, Brasília, DF, Brasil; $C P^{R} G$, 15 rue N.D. des Pauvres, 54500 Vandoeuvre, France 


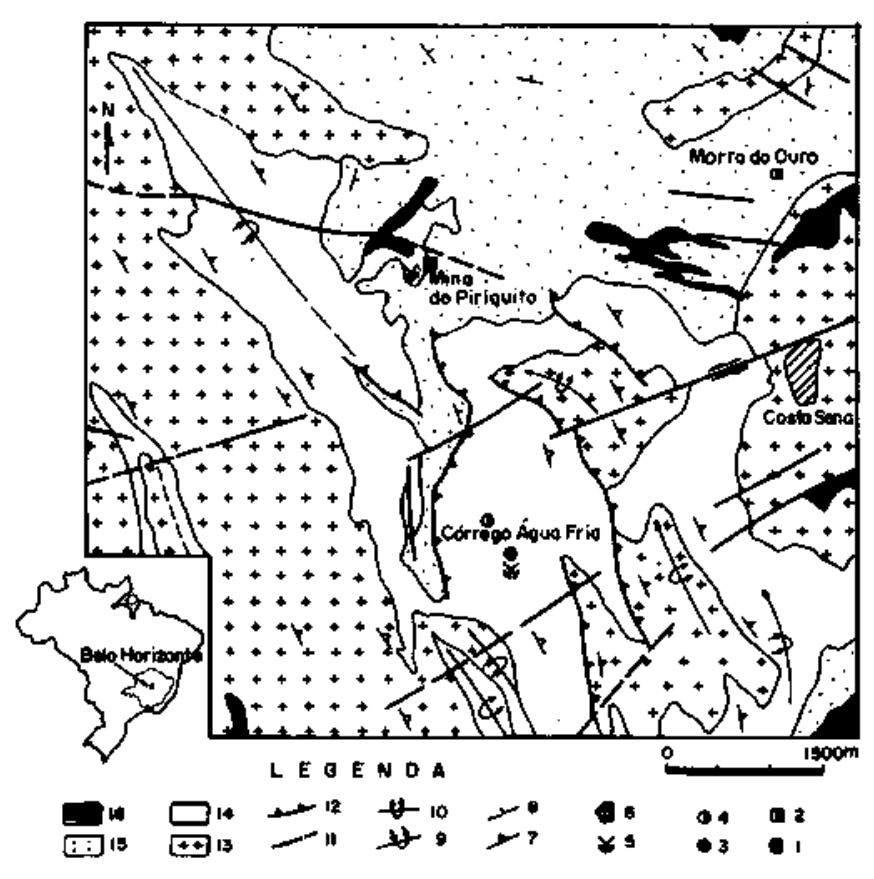

Figura 1-Mapa geológico da quadrícula da região de Costa Sena. Amostragem para o estudo de inclusões fluidas: $1 \mathrm{CF}$ 553; 2. CF 648; 3. CF 555; 4. CF 98; 5. mina abandonada; 6. vila de Costa Sena; 7. direção e mergulho de xistosidade, foliação cataclástica; 8. direção e mergulho de camada; 9. sinclinal invertido; 10. anticlinal invertido; 11. falha; 12. falha inversa. Terrenos arqueanos: 13. complexo granitico predominantemente cataclasado;14. Supergrupo Rio Paraúna (seqüencia vulcanossedimentar). Terrenos proterozóicos: 15. Supergrupo Espinhaço (Formação Sopa-Brumadinho); 16. Rochas magmáticas intrusivas (diques e massas de rochas básicas metamorfizadas)

Figure 1 - Geological map of Costa Sena region. Samples to the Fl study: 1. CF $553 ;$ 2. CF $648 ; 3$. CF $555 ;$ 4. CF $98 ; 5$. Periquito's mine; 6. Costa Sena village; 7 . schistosity strike and dip; 8 . bedding strike and dip; 9. reversed synclinal; 10. reversed anticlinal; 11. fault; 12. reversed fault. Archean terrain: 13. granitic complex; 14. Rio Paraúna Supergroup; Proterozoic terrain: 15. Espinhaço Supergroup (Sopa-Brumadinho formation); 16. intrusive igneous rocks (dykes and plugs of metabasic rocks)

senta quatro pequenas galenas (5 a $15 \mathrm{~m}$ de profundidade) e aparentemente os trabalhos se concentraram nos inúmeros veios de quartzo que recortam os quartzo-clorita xistos e sericita xistos. São veios de quartzo hialinos, com porções muito cisalhadas, geralmente subverticais e direções em torno de $\mathrm{N}-\mathrm{S}$, espessuras entre $5 \mathrm{~cm}$ e $1,5 \mathrm{~m}$, e que, neste caso, parecem constituir uma única geração.

Existem ainda duas outras ocorrências: a primeira próxima ao Córrego da Água Fria (a $3,3 \mathrm{~km}$ ao sul da mina do Periquito) e a outra no Morro do Ouro. Os veios de quartzo ocorrem ao longo de uma zona de fraturas e possuem direções preferenciais de $\mathrm{N} 20 \mathrm{~W}, 50 \mathrm{SW}$ e espessuras variáveis entre 0,4 e $50 \mathrm{~cm}$. Em todos os veios foi constatada a presença de hemamita especular.

O ouro é encontrado nas três ocorrências no estado nativo em pequenas pontuações dentro da ganga de quartzo.

\section{AS INCLUSÕES FLUIDAS ASSOCIADAS AO QUART- ZO AURÍFERO DE COSTA SENA Amostragem}

A seleção das amostras estudadas foi feita em função do conhecimento geológico da área em questão e tendo em vista que o estudo das inclusões fluidas é necessariamente complementar aos trabalhos básicos de geologia. Foram coletadas amostras nos três locais diferentes objetivando um estudo dos tipos de inclusões fluidas e sólidas, e da sucessão dos diversos fluidos presentes ou não nestes três locais.

Das cinco lâminas espessas polidas dos dois lados, duas são provenientes da mina do Periquito (CF 553 a.d.), duas das ocorrências do córrego da Água Fria (CF 98 e CF 555), e a quinta (CF 648) do Morro do Ouro (Fig. 1). Convém ressaltar que estas lâminas foram feitas de maneira a evitar qualquer aquecimento ou fraturação da amostra evitando-se assim danos às inclusões que podem ser, eventualmente, muito frágeis.

As amostras CF 555 e CF 98 foram coletadas nos planos de xistosidade (N30W, 40NE) dos sericita/clorita-xistos com turmalina, os quais sãç bastante semelhantes aos encontrados na mina do Periquito. E importante ressaltar que não se encontrou indícios da presença de ouro na ocorrência da amostra de quartzo CF 98.

No Morro do Ouro, foi coletada uma amostra de um veio de quartzo rico em hematita encaixado nos quartzitos e metaconglomerados Formação Sopa Brumadinho.

Procedimentos analíticos Os métodos analíticos utilizados durante este estudo de inclusões fluidas foram métodos não-destrutivos como a microscopia petrográfica clássica, a microtermometria e a espectrometria molar Raman.

A primeira fase do trabalho, descrição ao microscópio petrográfico, inclui observações sobre as características gerais das inclusões fluidas, tais como forma, tamanho, volume, número de fases presentes, distribuição e freqüência das inclusões. Sua importância é fundamental pois permite a classificação e estabelecimento da sucessão dos fluidos presentes.

A microtermometria abrange o aquecimento da inclusão até sua homogeneização, completa (Th), temperatura que, após a correção de calibração do aparelho, constitui a temperatura mínima na qual o fluido foi aprisionado. É possível, também, resfriar a inclusão até o congelamento completo das fases fluidas visando medir, posteriormente, a temperatura de fusão (Tf) do último fragmento de sólido $\left(\mathrm{H}_{2} \mathrm{O}\right.$ gelo ou $\mathrm{CO}_{2}$ sólido), a qual se relaciona diretamente com a salinidade da água ou pureza do $\mathrm{CO}_{2}$, respectivamente (Fuzikawa 1985). Para realizar este trabalho foi usada a platina de microtermometria Chaix Meca (Poty et al. 1976) que permite teoricamente resfriamentos até $-180,0^{\circ} \mathrm{C}$ e aquecimentos até $+600,0^{\circ} \mathrm{C}$. A reprodutibilidade das medidas é estimada em aproximadamente $0,5^{\circ} \mathrm{C}$.

A espectrometria molar Raman, método especialmente apropriado ao estudo das inclusões fluidas na medida em que é nãodestrutivo e pontual, permite determinações qualitativas e quantitativas das fases presentes. $\mathrm{O}$ efeito Raman se manifesta pelo fato de que a luz monocromática (laser) pode ser difundida nas estruturas poliatômicas em freqüências diversas e características das ligações moleculares presentes (Rosasco \& Simmons 1974, Delhaye \& Dhamelincourt 1975). Os espectros assim obtidos permitem a identificação das espécies químicas qualquer que seja o estado da matéria. $\mathrm{O}$ espectrômetro Raman usado é do tipo U 1000 (Jobin-Yvon) equipado de um microscópio Olympus (CNRS-BRGM - Université d'Orleans, França). A radiação excitatriz necessária à obtenção do efeito Raman possui um comprimento de onda de $514,5 \mathrm{~nm}$ e é fornecida por um laser com argônio ionizado (Coherent tipo Innova 90).

Tipos de inclusões fluidas Os tipos de inclusões fluidas observadas nos veios de quartzo nas três ocorrências auríferas à temperatura ambiente foram os seguintes:

1. Tipo C - Aquo-carbônica, dois subtipos, $\mathrm{C}_{1}$ e $\mathrm{C}_{2}$ precoces, geralmente trifásicas a $2 \mathrm{O}^{\circ} \mathrm{C}$, eventualmente com sólidos acidentais. $\mathrm{H}_{2} \mathrm{O}+\mathrm{CO}_{2}$ líquido $+\mathrm{CO}_{2}$ vapor + sólidos acidentais (incolor alta birrefringência: calcita e incolor: quartzo). 2. Tipo Lc - Aquo-carbônica, precoce (primária?), bifásica. $\mathrm{H}_{2} \mathrm{O}+\mathrm{NaCl}-\mathrm{i}-\mathrm{CO}_{2}$. 


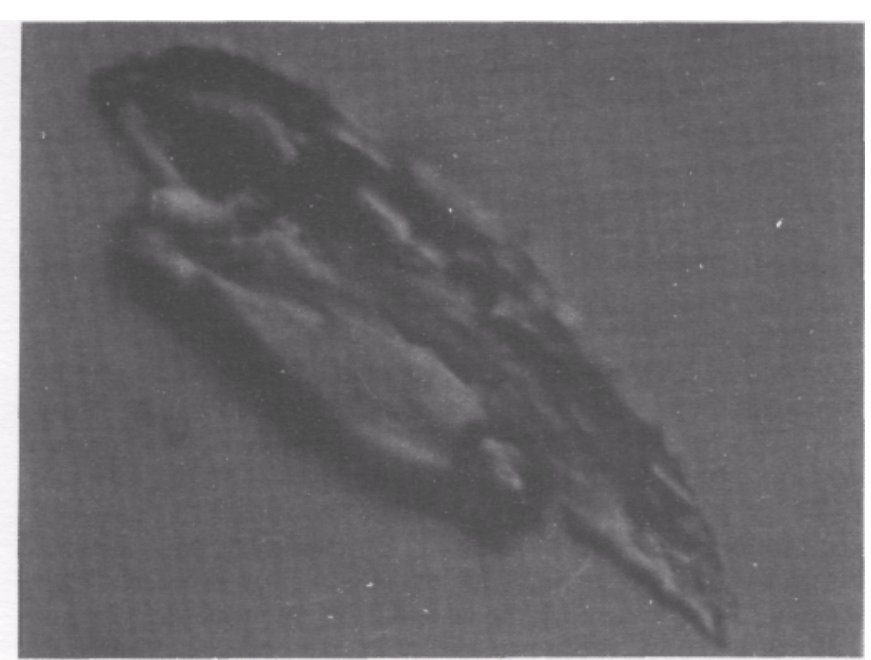

1
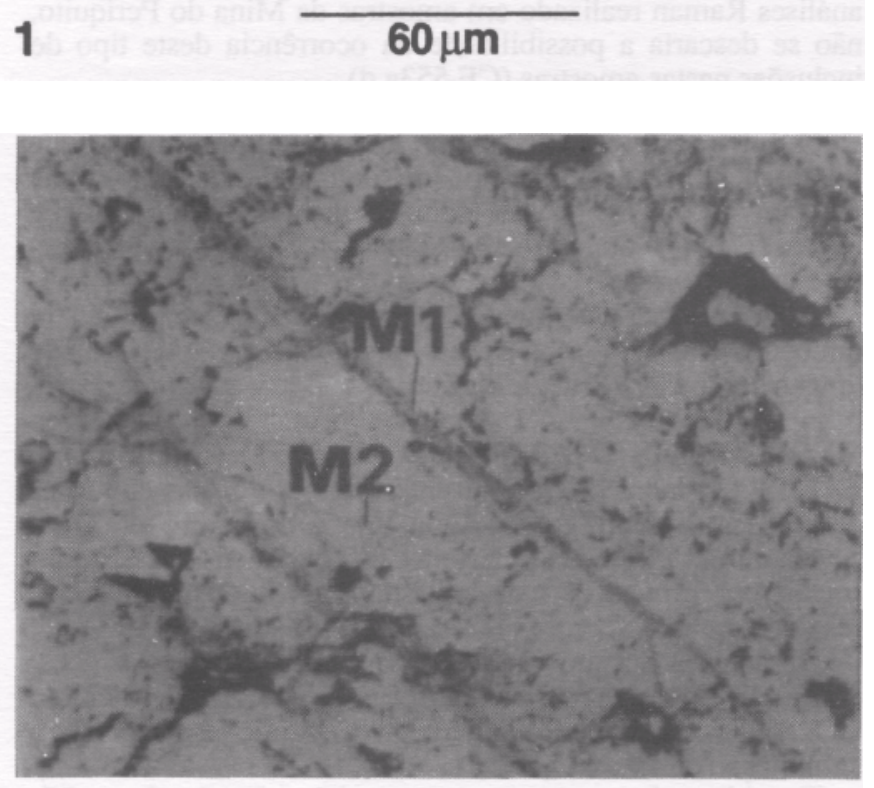

3

$5 \mathrm{~mm}$

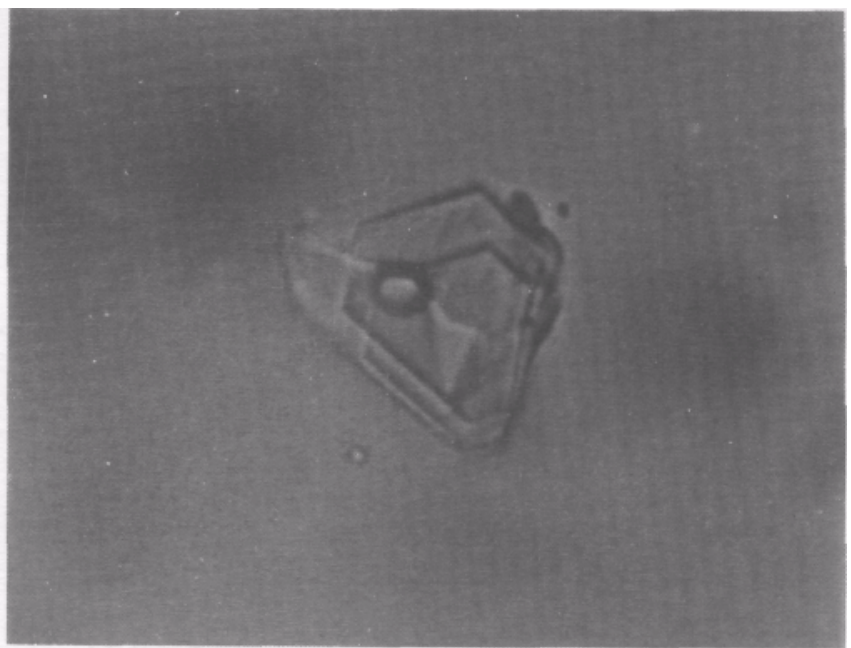

2

$40 \mu \mathrm{m}$

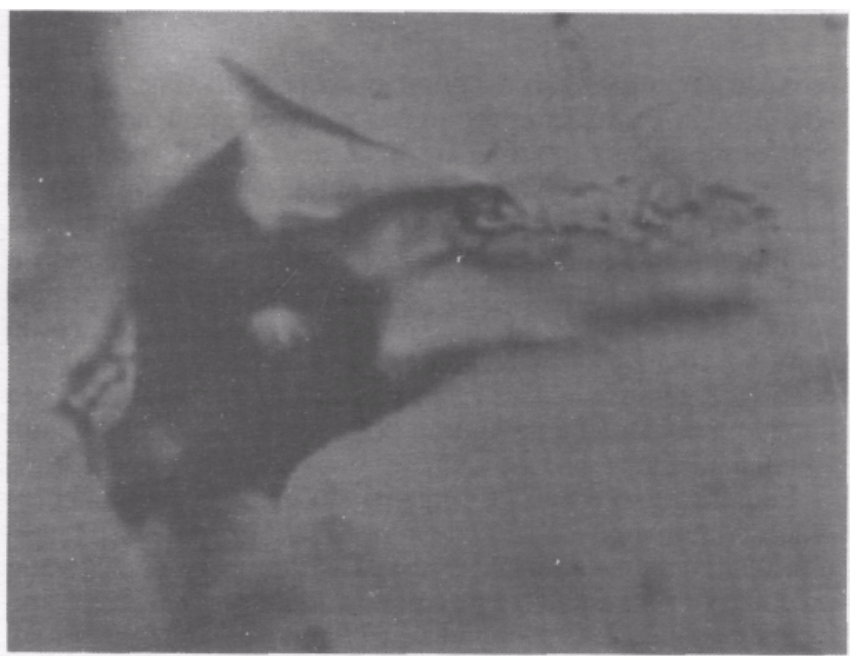

4

Prancha 1 - Fotomicrografias: 1. Inclusão fluida aquq-carbônica, tipo Cl, amostra CF 555, Córrego da Água Fria. 2. Inclusão fluida aquosa, tipo Lc, amostra CF 555, Córrego da Agua Fria. Observar o crescimento helicoidal das paredes da inclusão. 3. Alinhamento de inclusões fluidas, monofásicas, tipo M1 e M2, aquosas, secundárias. 4. Grande inclusão fluida aquosa, encontrada em microgeodo entre grãos de quartzo

Plate 1 - Photomicrographs: 1. Aquo-carbonic fluid inclusion, Type Cl, Cf 555 sample, Córrego da Água Fria. 2. Aquous fluid inclusion, Type Lc, CF 555 sample, Córrego da Água Fria. See the helicoidal frowth of the inclusion walls. 3. Mono phased fluid inclusions alignments, Types Ml and M2, aqueous, secundanes. 4. Big aqueous fluid inclusion, found as a microdruse

3. Tipo L - Aquosa $\left(\mathrm{L}_{1}\right.$ e $\left.\mathrm{L}_{2}\right)$, tardia (pseudo-secundária?), bifásica. $\mathrm{H}_{2} \mathrm{O}+\mathrm{NaCl}+$ sólido acidental pontual não-identificado.

4. Tipo $\mathrm{M}$ - Aquosa $\left(\mathrm{M}_{1}\right.$ e $\left.\mathrm{M}_{2}\right)$, secundária, monofásica.

O tipo C, encontrado no Córrego da Água Fria, apresenta formas irregulares e por vezes com contornos rudimentarmente cúbicos ou hexagonais. Algumas são planas e ocorrem isoladamente ou em pequenos grupos; são comuns as evidências de estrangulamento (necking down). Os tamanhos variam entre 10 e $80 \mu \mathrm{m}$ e o volume da fase $\mathrm{CO}_{2}$ líquido $+\mathrm{CO}_{2}$ vapor, embora possa variar, geralmente está por volta de $15 \%$. Essas inclusões representam também em torno de $15 \%$ do total das inclusões estudadas.

As inclusões aquo-carbônicas encontradas no Morro do Ouro possuem aproximadamente as mesmas características morfológicas do tipo C encontrado no Córrego da Água Fria.
Entretanto, suas evidências de estrangulamento são mais nítidas e as inclusões ocorrem em grupos grosseiramente alinhados (Fig. 2), o volume da fase $\mathrm{CO}_{2}$ é maior, por volta de $20 \%$ e são encontradas proporcionalmente em maior número, representando $20 \%$ das inclusões estudadas. Estas diferenças observadas entre as inclusões aquo-carbônicas do Córrego da Água Fria e do Morro do Ouro permitem suspeitar a circulação de dois fluidos com componentes carbônicos, denominados $\mathrm{C}_{1} \mathrm{e}$ $\mathrm{C}_{2}$ respectivamente.

Não foram observados sólidos de saturação nas inclusões aquo-carbônicas, entretanto ocorrem os seguintes tipos de sólidos acidentais: 1. incolor de alta birrefringência (principalmente nas amostras CF 555 e 648) que também é encontrado como inclusão sólida no quartzo, tendo sido, nos dois casos, identificado como calcita pelo espectrômetro Raman (Fig. 2, inclusões números 1, 3,5, 12 e 16); 2. sólido incolor, índice de 


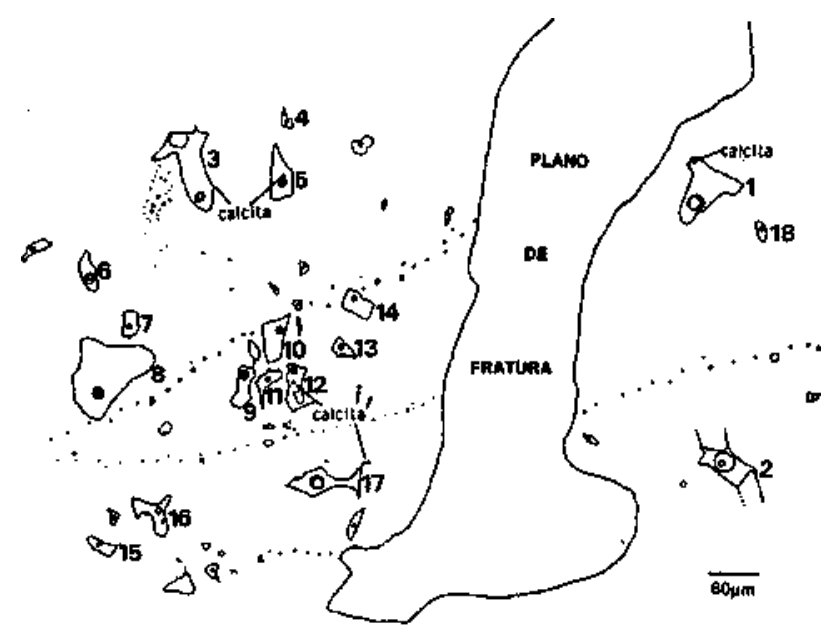

Figura 2 - Distribuição e relações das inclusões fluidas dos tipos $\mathrm{C}_{2}$ e L na amostra CF 648 (Morro do Ouro)

Figure 2 - The $\mathrm{C} 2$ and $\mathrm{L}$ fluid inclusions types in the sample CF 648 (Morro do Ouro)

refração semelhante ao do quartzo hospedeiro (Fig. 2, inclusões 3 e 12) ocorre em proporções variáveis, podendo preencher desde menos de $10 \%$ até mais de $70 \%$ do volume das inclusões de tipo C. Não se altera durante o aquecimento. O raio laser do Raman ao incidir sobre este sólido apresentou um comportamento semelhante ao observado sobre o quartzo e nitidamente diferente daquele ao incidir sobre o líquido. Este sólido possivelmente do quartzo hospedeiro que, de acordo com a forma ou durante processos de estrangulamento, foi envolvido pelas inclusões criando, conforme o corte efetuado durante a preparação da lâmina polida, a ilusão óptica de um sólido acidental.

Finalmente, o tipo $\mathrm{C}_{1}$ é considerado precoce por sua ocorrência comumente isolado ou em pequenos grupos e seu tamanho relativamente grande. $\mathrm{O}$ tipo $\mathrm{C}_{2}$ é também considerado precoce por suas inclusões de calcita que são encontradas como inclusões sólidas.

O tipo Lc é diferenciado do tipo $\mathrm{C}$ pelo fato de a temperatura ambiente apresentar-se bifásica. A fraca presença de $\mathrm{CO}_{2}$, característica deste tipo, é identificada apenas pelo espectrômetro Raman. Foram consideradas como precoces pelo nítido crescimento helicoidal de pelo menos uma dessas inclusões. É possível que este tipo tenha se formado pelo estrangulamento do tipo $\mathrm{C}$ ou contaminação do tipo L. Porém, convém ressaltar que uma inclusão com crescimento helicoidal e hábito hexagonal, claramente isolada, deve ser uma amostra pontual do fluido mineralizante original.

O tipo $\mathbf{L}$ constitui $65 \%$ do número total de inclusões fluidas estudadas. Abrange inclusões bifásicas aquosas, com $\mathrm{NaCl}$ e provavelmente outros cations (primeira temperatura de fusão do gelo sempre inferior a $\left.-30, \mathrm{O}^{\circ} \mathrm{C}\right)$. Possui formas poligonais irregulares e arredondadas, sendo em geral menores que os tipos C e Lc, com tamanhos entre 10 e $20 \mu \mathrm{m}$. Apresenta entre 10 e $20 \%$ do volume total da cavidade. Comumente, formam alinhamentos grosseiros, o que indica sua origem relativamente tardia.

Os tipos C, Lc e L podem eventualmente ocorrer associados em um mesmo alinhamento especialmente no Morro do Ouro (CF 648).

O tipo $\mathrm{M}$, inclusões monofásicas, das quais existem ao menos duas gerações: $M_{1}$ - possivelmente a mais antiga, com alinhamentos bem marcados de inclusões monofásicas, por vezes bifásicas, possuem formas arredondadas e tamanhos inferiores a $6 \mu \mathrm{m}$. Estes alinhamentos são, aparentemente, cortados por outros alinhamentos de inclusões fluidas monofásicas secundárias, tipo $\mathrm{M}_{2} \cdot \mathrm{M}_{2}$ - Inclusões fluidas monofá- sicas menores que o tipo $\mathrm{Mi}$, tamanhos da ordem de $1 \mu \mathrm{m}$, arredondadas e alongadas, formam um alinhamento muito fino e nítido. É possível encontrar inclusões fluidas monofásicas maiores que $10 \mu \mathrm{m}$, em geral associadas a pequenos grupos de inclusões dos tipos $\mathrm{C}$ ou $\mathrm{L}$, que poderiam ser o resultado de processos de estrangulamento.

Espectrometria Molar Raman Foram realizadas análises nas fases gasosas, liquidasse sólidas em todos os tipos de inclusões. No Córrego da Água Fria, confirmou-se a presença de $\mathrm{CO}_{2}$ e possíveis traços de $\mathrm{CH}_{4}$ ao passo que no Morro do Ouro o $\mathrm{CO}_{2}$ é praticamente puro (Fig. 3).

$\mathrm{O} \mathrm{CO}_{2}$ foi detectado em pequenas proporções no Tipo Lc do Córrego da Água Fria e Morro de Ouro (lâminas CF 555, 648 e 98) não sendo observados picos significativos nas faixas correspondentes ao $\mathrm{CH}_{4}, \mathrm{H}_{2} \mathrm{~S}$ e $\mathrm{N}_{2}$. Em contraste, nas inclusões bifásicas do Tipo L nada foi detectado pela espectrometria Raman, tratando-se portanto de inclusões meramente aquosas. Embora não observadas e tendo em vista o pequeno número de análises Raman realizado em amostras da Mina do Periquito, não se descarta a possibilidade da ocorrência deste tipo de inclusões nestas amostras (CF 553a,d).

O único sólido positivamente identificado foi aquele que possui alta birrefringência e ocorre tanto como inclusão sólida no quartzo, como dentro das inclusões de tipo $\mathrm{C}$ e L, trata-se de calcita (Fig. 4). Sobre os demais sólidos não foi possível detectar sua composição.

A fase aquosa dos diferentes tipos de inclusões fluidas foi também analisada mas a espectrometria não revelou traços de ânions como $\mathrm{CO}_{3}^{2-}, \mathrm{HCO}_{3}^{-}$ou $\mathrm{SO}_{4}^{2-}$.

RESULTADOS DO ESTUDO MICROTERMOMÉTRICO Os dados microtermométricos obtidos nas inclusões carbônicas do Córrego da Água Fria e do Morro do Ouro revelaram-se diferentes em todos os parâmetros físico-químicos, confirmando a existência de dois fluidos carbônicos, respectivamente, $\mathrm{C}_{1}$ e $\mathrm{C}_{2}$ (Tab. 1).

Durante o resfriamento até $-130^{\circ} \mathrm{C}$, das inclusões $\mathrm{C}_{1}(\mathrm{CF}$ 555), não é possível observar a formação do clatrato, nem do $\mathrm{CO}_{2}$ sólido, é de maneira imperceptível, supõe-se que ocorra a sublimação da fase $\mathrm{CO}_{2}$.

Considerando-se que a homogeneização da fase $\mathrm{CO}_{2}$ $\left(\mathrm{ThCO}_{2}\right)$ e total (Th) pode ocorrer da forma líquida (1) ou vapor (v) o tipo $\mathrm{Cl}$ pode ser subdividido em C1II e Cl VI.

Por outro lado, as inclusões $\mathrm{C}_{2}$ (CF 648) quando mais "ricas" em $\mathrm{CO}_{2}$, em regra congelam sua fase aquosa durante o resfriamento entre $-35,0$ e $-45,0^{\circ} \mathrm{C}$, fato este que implica em redução do volume da bolha de $\mathrm{CO}_{2}$ líquido $+\mathrm{CO}_{2}$ vapor, a qual, geralmente, assume instantaneamente uma forma lenticular. Entre $-50,0^{\circ} \mathrm{C}$ e $-60,0^{\circ} \mathrm{C}$ a parte mais externa desta lente também solidifica-se, este duplo congelamento, de acordo com Collins (1979) é indício da formação do clatrato $\left(\mathrm{CO}_{2} .5,75\right.$ $\mathrm{H}_{2} \mathrm{O}$ ). $\mathrm{O}$ congelamento do $\mathrm{CO}_{2}$ remanescente, caso ainda exista algum, ocorre por volta de $-100,0^{\circ} \mathrm{C}$, momento no qual a forma lenticular já desapareceu. $\mathrm{A}$ bolha de $\mathrm{CO}_{2}$ líquido $+\mathrm{CO}_{2}$ vapor retorna gradualmente à proporção que as fases solidificadas são fundidas durante o reaquecimento da inclusão. A fusão do $\mathrm{CO}_{2}$ $\left(\mathrm{TF} \mathrm{CO}_{2}\right.$ ) ocorre em média a $-56,9^{\circ} \mathrm{C}$, em temperaturas próximas ao ponto de fusão teórico do $\mathrm{CO}_{2}$ puro $\left(-56,6^{\circ} \mathrm{C}\right)$. A observação da fusão do gelo $\left(\mathrm{H}_{2} \mathrm{O}\right)$ é dificultada, mas não impedida pela formação do clatrato, e a decomposição deste último é claramente observada em presença de $\mathrm{CO}_{2}$ líquido e vapor (inclusão é trifásica no momento). A salinidade das inclusões tipo $\mathrm{C}$ foi calculada a partir da temperatura de decomposição do clatrato de acordo com Bozzo et al. (1973) e Collins (1979).

Os tipos Lc e L, bifásicos à temperatura ambiente, foram encontrados em quase todas as amostras de quartzo de Costa Sena não sendo possível distingui-los por meio da microtermometria. 




Figura 3 - Espectro Raman de uma inclusão fluida aquo-carbônica, tipo $C_{1}$, amostra CF 555, Córrego da Água Fria. Constata-se a presença de $\mathrm{CO}_{2}$ e possíveis traços de $\mathrm{CH}_{4}$. Laser power: $514 \mathrm{~nm}, 800 \mathrm{mw}$, slits: $500 \mu$, objetiva x150 água, 1500v, CTS/SEC contagens por segundo, $R C M-1$ = número de onda relativo em $\mathrm{cm}^{-1}$

Figure 3 - Raman spectrum of a aquo-carbonic fluid inclusion, type $\mathrm{C}_{1}$, sample CF 555, Córrego da Água Fria. There is $\mathrm{CO}_{2}$ and possible traces of $\mathrm{CH}_{4}$. Laser power: $514 \mathrm{~nm} .800 \mathrm{mw}$. slits: $500 \mu$. objetive x 150 water. $1.500 \mathrm{v}$

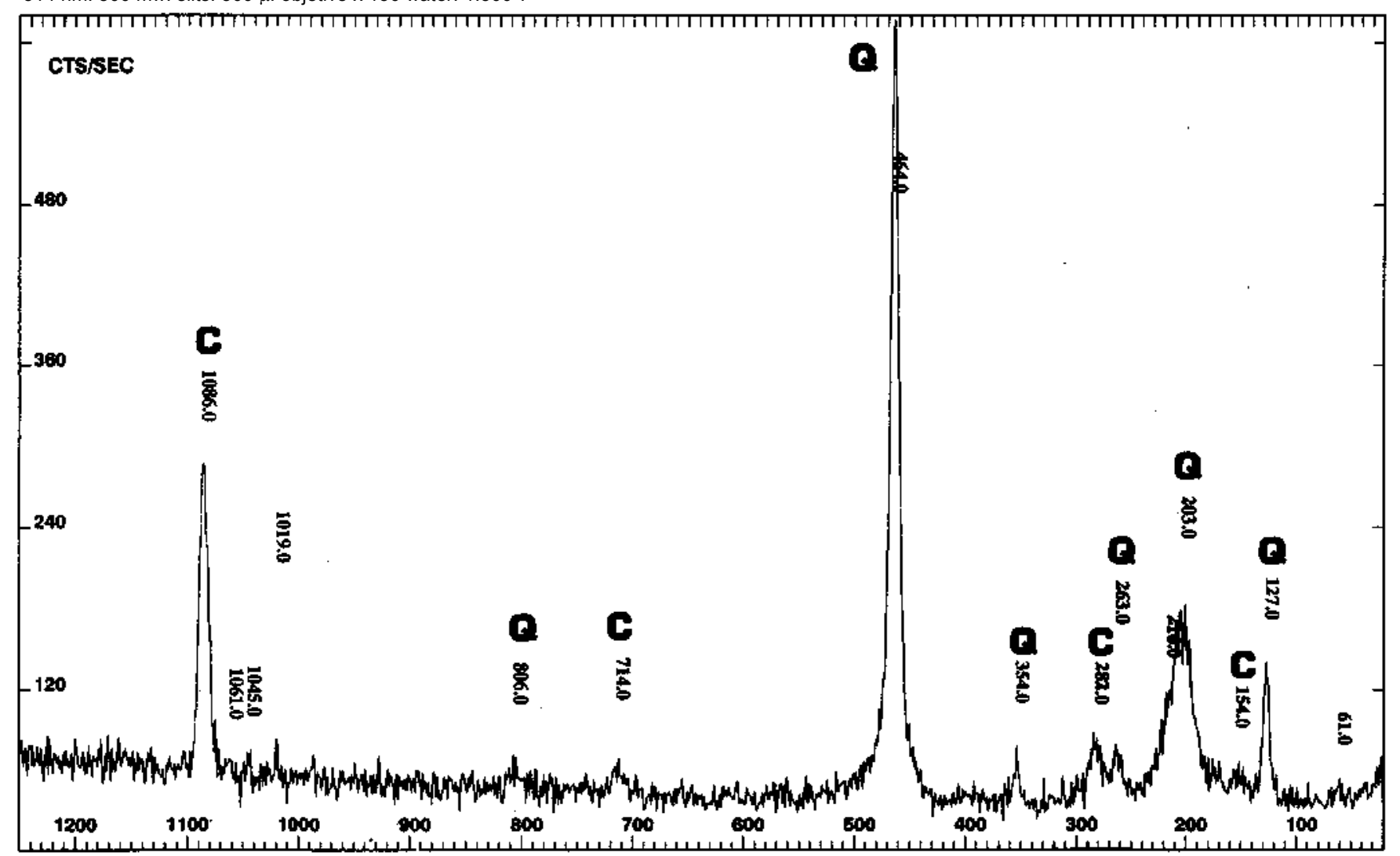

Figura 4 - Espectro Raman sobre a calcita encontrada dentro da inclusão fluida tipo $\mathrm{CO}_{2}$ (amostra CF 648 - Morro do Ouro) Figure 4 - Raman spectrum in a calcite trapped crystal in a $\mathrm{CO}_{2}$ type fluid inclusion (sample CF 648 - Morro do Ouro) 
Tabela 1 - Comparação dos dados microtermométricos obtidos nas inclusões carbônicas tipo $C_{l}$ (Córrego da Água Fria) e tipo $\mathrm{C}_{2}$ (Morro do Ouro). $\mathrm{VF} \mathrm{CO}_{2} \%=$ volume da fase $\mathrm{CO}_{2}$ (líquida + gasosa); $\boldsymbol{T f} \boldsymbol{C O}_{2}{ }^{\circ} \boldsymbol{C}=$ temperatura de fusão da fase $\mathrm{H}_{2} \mathrm{O}$ gelo em ${ }^{\circ} \mathrm{C} ; \boldsymbol{T d}$ clat ${ }^{\circ} \mathrm{C}=$ temperatura de decomposição do clatrato em ${ }^{\circ} \mathrm{C} ; \boldsymbol{T h} \boldsymbol{C O}_{2}{ }^{\circ} \boldsymbol{C}=$ temperatura de homogeneização da fase $\mathrm{CO}_{2} \mathrm{em}{ }^{\circ} \mathrm{C}$, (I - na fase líquida, $\boldsymbol{g}$ - na fase vapor); $\boldsymbol{T h}{ }^{\circ} \mathbf{C}=$ temperatura de homogeneização total em ${ }^{\circ} \mathrm{C}$, ( $\boldsymbol{I}$ - na fase líquida, $\boldsymbol{g}$ - na fase vapor); $\boldsymbol{T} \boldsymbol{c}{ }^{\circ} \boldsymbol{C}=$ temperatura de crepitação em ${ }^{\circ} \mathrm{C}$; salinidade em \% peso equivalente $\mathrm{NaCl}$ obtida a partir dos dados de decomposição do clatrato; $\boldsymbol{d} \mathbf{C O}_{2}$ $=$ densidade da fase $\mathrm{CO}_{2} \mathrm{em} \mathrm{g} / \mathrm{cm}^{3} ; \boldsymbol{d}$ total = densidade total da inclusão em $\mathrm{g} / \mathrm{cm} 3$. * Inclusão que sofreu vazamento, máx. = valores máximos; $\boldsymbol{m i n} .=$ valores mínimos; freq. $=$ número de inclusões estudadas

Table 1 - Microthermometric data of the aquo-carbonic inclusions type $\mathrm{Q}$ and $\mathrm{C}_{2}: \mathbf{V F ~} \mathrm{CO}_{2} \%=\mathrm{CO}_{2}$ phase volume (liquid + vapor), $\mathrm{Tf} \mathrm{CO}_{2}{ }^{\circ} \mathrm{C}=$ melting temperature of the solid $\mathrm{CO}_{2}$ phase in ${ }^{\circ} \mathrm{C}$; $\mathbf{T f} \mathbf{H}_{2} \mathbf{O}^{\circ} \mathbf{C}=$ melting temperature of the ice $\mathrm{H}_{2} \mathrm{O}$ phase in ${ }^{\circ} \mathrm{C}$; $\mathbf{T d}$ clath ${ }^{\circ} \mathbf{C}=$ decomposition temperature of the clathrate in ${ }^{\circ} \mathrm{C}$; $\mathbf{T h} \mathbf{C O}_{2}{ }^{\circ} \mathbf{C}=$ Homogenizations temperature of the $\mathrm{CO}_{2}$ phase in ${ }^{\circ} \mathrm{C}$ (I - liquid phase, $\mathrm{g}$ - vapor phase); $\mathbf{T h}{ }^{\circ} \mathrm{C}=$ total homogenization temperature in ${ }^{\circ} \mathrm{C}\left(\mathbf{I}\right.$ - liquid phase, $\mathbf{g}$ - vapor phase); $\mathbf{T c}{ }^{\circ} \mathbf{C}=$ decrepitation temperature in ${ }^{\circ} \mathrm{C}$; salinity in weight $\%$ eq. $\mathrm{NaCl}$ calculated in relation of the clathrate temperature decomposition; $\mathbf{d} \mathbf{C O}_{2}=\mathrm{CO}_{2}$ phase density in $\mathrm{g} / \mathrm{cm}^{3} ; \mathbf{d}$ total $=$ inclusion total density in $\mathrm{g} / \mathrm{cm}^{3}$. * Inclusion that undergo leakage, máx. = maximum values; mín. $=$ minimum values; freq. $=$ number of studied inclusions

\begin{tabular}{|c|c|c|c|c|c|c|}
\hline \multirow{4}{*}{ 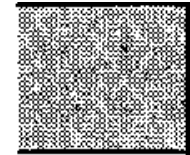 } & \multicolumn{3}{|c|}{ C1 } & \multicolumn{3}{|c|}{ C2 } \\
\hline & Córrego & Agua & Fria & Morro & do & Quro \\
\hline & CF 555 & & 17 incl & CF 648 & & 52 incl \\
\hline & min & $\operatorname{msx}$ & $n^{\circ}$ med & $\min$ & máx & $n^{\circ} \operatorname{med}$ \\
\hline VFCO2\% & 12 & 20 & 15 & 10 & 30 & 45 \\
\hline $\mathrm{co}$ & năo & obs. & & $-57,7$ & $-56,1$ & 13 \\
\hline $\mathrm{H} 2 \mathrm{O}$ & $-7,5$ & $-5,1$ & 16 & $-15,7$ & .12 & \\
\hline $\operatorname{delat}^{\circ} \mathrm{C}$ & 6,5 & & & .07 & 2,2 & 3 \\
\hline${ }^{\circ} \mathrm{C}$ & 22,5 & 29 & & $3, \overline{4}$ & 30,5 & 1 \\
\hline g & .3) & 2 & & 3 & 31,2 & 12 \\
\hline 1 & .9 & 179.5 & 9 & 149,8 & 347 & 21 \\
\hline a & & & & 279.2 & 445,3 & \\
\hline${ }^{\circ} \mathrm{C}$ & 53,7 & 231,5 & 6 & 152,5 & 268,4 & \\
\hline Salinidade & 6 & 7 & $\circ$ & 13,2 & 15,1 & 33 \\
\hline $\mathrm{CO} 2$ & 34 & 0,75 & 1 & 0.28 & 0,74 & 20 \\
\hline total & 0,91 & 1,014 & & 0.93 & 1,047 & 20 \\
\hline 202 & 4,2 & 8,9 & 7 & 5,9 & 22,4 & 20 \\
\hline
\end{tabular}

Quatro inclusões foram identificadas com o espectrômetro Raman claramente como tipo Lc e apresentaram as seguintes salinidades e temperaturas de crepitação (esta última obtida em apenas duas inclusões): $8,0 \%$ peso eq. $\mathrm{NaCl}$ e $153,5^{\circ} \mathrm{C}, 10,0 \%$ peso eq. $\mathrm{NaCl}$ ( $\mathrm{CF} 555) ; 15,1 \%$ peso eq. $\mathrm{NaCl}$ (CF 98); e $10,6 \%$ peso eq. $\mathrm{NaCl}$ e $185,0^{\circ} \mathrm{C}$ (CF 648). A salinidade destas quatro inclusões é sempre semelhante à de suas vizinhas, e aquela da lâmina CF 648, que ocorre em um alinhamento do tipo L, apresentou sinais de vazamento antes das medidas, o que sugere a hipótese de contaminação para a origem desta inclusão.

Verificando-se os histogramas de temperaturas de fusão do gelo e salinidade, que apresentam dois picos evidentes, um a $-5,0^{\circ} \mathrm{C}$ (salinidade 7 a $8 \%$ eq. peso $\mathrm{NaCl}$ ) e outro a $-9,0^{\circ} \mathrm{C}$ (salinidade 13 a $14 \%$ eq. $\mathrm{NaCl}$, Fig. 5 e 6 ) pode-se subdividir o tipo $\mathrm{L}$, respectivamente em tipos $\mathrm{L}_{1}$ e $\mathrm{L}_{2}$ (Tab. 2). No histograma de freqüência de temperatura de homogeneização (Fig. 7), a diferença dos tipo $\mathrm{L}_{1}$ e $\mathrm{L}_{2}$ é menos marcante devido à dispersão das $\mathrm{Th}$, possivelmente em decorrência dos processos de estrangulamento.

Três medidas de fusão do gelo foram observadas em torno de 0 e $-1^{\circ} \mathrm{C}$, correspondendo a grandes inclusões, encontradas nos interstícios dos grão de quartzo, formando microgeadas e com especularita como sólido acidental.

No diagrama de temperaturas de homogeneização x salinidade (Fig. 8), verifica-se que cada um dos tipos definidos $\left(\mathrm{C}_{1}, \mathrm{C}_{2}, \mathrm{~L}_{1}\right.$ e $\left.\mathrm{L}_{2}\right)$ ocupa um domínio próprio. $\mathrm{O}$ tipo $\mathrm{Lc}$ não possui dados confiáveis em número suficiente para ser representado. Entretanto, é interessante ressaltar a distribuição da salinidade destas inclusões que está dispersa entre 8 e $15,1 \%$ eq. peso $\mathrm{NaCl}$.

As inclusões monofásicas do tipo $\mathrm{M}$ são pequenas demais para fornecerem dados sobre sua salinidade. Entretanto, as citadas inclusões monofásicas maiores e associadas aos tipos $\mathrm{L}_{1}$ e $\mathrm{L}_{2}$ apresentaram em média $-1,5$ (7 medidas) e $-8,7$ (9 medidas), que se aproximam dos tipos $\mathrm{L}_{1}$ e $\mathrm{L}_{2}$ respectivamente. Possivelmente, são inclusões formadas por estrangulamento.

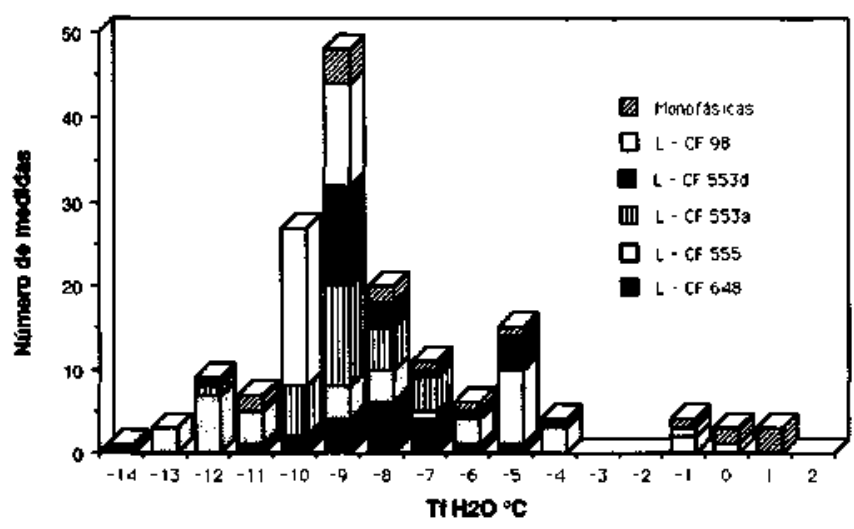

Figura 5 - Distribuição das temperaturas de fusão do gelo $\left(\mathrm{H}_{2} \mathrm{O}\right)$ das inclusões tipos $\mathrm{L}$, Lc e M. O tipo $\mathrm{L}_{1}$ possui salinidades entre -4 e $-6{ }^{\circ} \mathrm{C}$ e o tipo $L_{2}$ entre -6 e $-14{ }^{\circ} \mathrm{C}$. E $\mathrm{E}$ impossivel diferenciar o tipo Lc do tipo $L$ por meio da microtermomefria. CF 98, CF 555: amostras do Córrego da Água Fria, CF 553 a,d: amostras da mina do Periquito, $C F$ 555: amostra do Morro do Ouro

Figure 5 - Histograms of the meltings point of ice of the types L, Lc and M inclusion. The type $\mathrm{L}_{1}$ has salinities from -4 to $-6^{\circ} \mathrm{C}$ and the type $\mathrm{L}_{2}$ from -6 to $14^{\circ} \mathrm{C}$. There is no difference between types $\mathrm{Lc}$ and $\mathrm{L}$ only by microthermometric data. CF 98 and CF 555: samples from Córrego da Água Fria, CF 553 a, d: samples from Mine of Periquito, CF 555: sample from Morro do Ouro

INTERPRETAÇÃO DOS DADOS MICROTERMOMÉTRICOS O estrangulamento (necking down) das inclusões é evidenciado por sua morfologia característica (Fig. 2). E também sugerido pela ocorrência de diversas inclusões com salinidade constante e Th variável, formando tendências verticais (Fig. 8), especialmente na ocorrência de quartzo CF 98 do Córrego da Água Fria, cuja salinidade corresponde ao tipo $\mathrm{L}_{2}$ (Fig. 9). Este tipo de alteração pós-formacional, em geral, faz com que os histogramas de Th sejam achatados e dispersos sem nenhum pico máximo bem definido e pode provocar uma forte dispersão dos valores da densidade (ao alterar o volume da fase $\mathrm{CO}_{2}$ ). Entretanto, os dados de salinidade permanecem confiáveis. Em seguida, são discutidas as outras possibilidades de interpretação de tendências verticais.

Outro tipo de alteração pós-formacional, o vazamento (leakage) observado de diversas inclusões fluidas, eventualmente, durante o aquecimento de algumas inclusões em todas as amostras estudadas, é caracterizado por um súbito aumento do volume da fase gasosa. Estes dados são registrados como temperatura de crepitação e, apesar de constituírem temperaturas mínimas de formação, não foram usados na construção de histogramas ou diagramas $\mathrm{Th} \mathrm{x}$ salinidade. Apenas quatro inclusões do tipo $\mathrm{C}_{2}$ homogeneizaram na fase gasosa (Fig. 8). 




Figura 6 - Distribuição cia salinidade observada nas inclusões tipos $C_{1}$ e $C_{2}$ (calculada a partir da dissolução do clatrato) $e$ $\mathrm{L}_{2}$ (calculada apartirdajíisão do gelo $\left.H-f\right)$ ). $L_{1}$ possui salinidade em tomo de $8 \%$ peso eq. NaCl e $L_{2}$ em torno de $13 \%$ peso eq. $\mathrm{NaCl}$

Figure 6 - Histogram of the salinity in the types $C_{1}$ and $C_{2}$ inclusions (from clathrate dissolution) and $\mathrm{L}$ (from ice melting). The type $\mathrm{L}_{1}$ has salinities near of wt. \% eq. $\mathrm{NaCl}$ and $\mathrm{L}_{2}$ near 13 wt. \% eq. $\mathrm{NaCl}$

Tabela 2 - Comparação dos dados microtermométrícos obtidos nas inclusões fluidas aquosas tipos $L_{1}$ e L2 na Mina do Periquito (CF 553 a,d). Córrego da Água Fria (CF 98 e 555) e Morro do Ouro (CF 648). $\boldsymbol{T} \boldsymbol{f} \boldsymbol{H}_{2} \boldsymbol{O}=$ temperatura de fusão do gelo $\left(\mathrm{H}_{2} \mathrm{O}\right)$ em ${ }^{\circ} \mathrm{C} ; \boldsymbol{S a l} .=$ salinidade em $\%$ peso equivalente $\mathrm{NaCl} ; \boldsymbol{T h}=$ temperatura de homogeneização total em ${ }^{\circ} \mathrm{C}$ Table 2 - Microthermometric data of the aquous fluid inclusion type $\mathrm{L}_{1}$ and $\mathrm{L}_{2}$ in Periquito's mine (CF 553 a, d); Córrego da Á gua Fria (CF 98 and CF 555) and Morro do Ouro (CF 648). Tf $\mathbf{H}_{2} \mathbf{O}=$ ice $\mathrm{H}_{2} \mathrm{O}$ melting temperature in ${ }^{\circ} \mathrm{C}$, Sal. $=$ salinity in weight $\%$ eq. $\mathrm{NaCl} ; \mathrm{Th}=$ total homogenization temperature in ${ }^{\circ} \mathrm{C}$
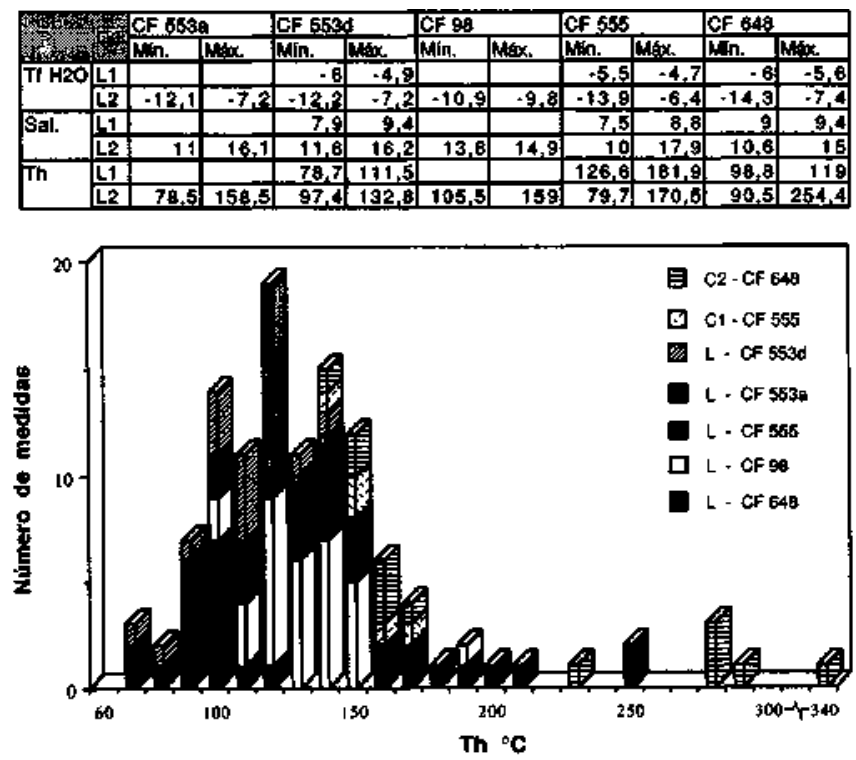

Figura 7 - Distribuição das temperaturas de homogeneização das inclusões tipos $\mathrm{L}, \mathrm{C}_{1}$ e $\mathrm{C}_{2}$

Figure 7 - Histogram of the homogenization temperature of the types $\mathrm{L}, \mathrm{C}_{1}$ and $\mathrm{C}_{2}$ inclusions

Considerando que suas Th são anomalamente altas e que seu volume de fase gás antes do aquecimento era de $20 \%$, é evidente que sua homogeneização na fase gasosa é devida a vazamento, possivelmente seguido de rápida cicatrização da fissura que teria permitido este vazamento parcial. Todos os dados suspeitos de vazamento foram desconsiderados.

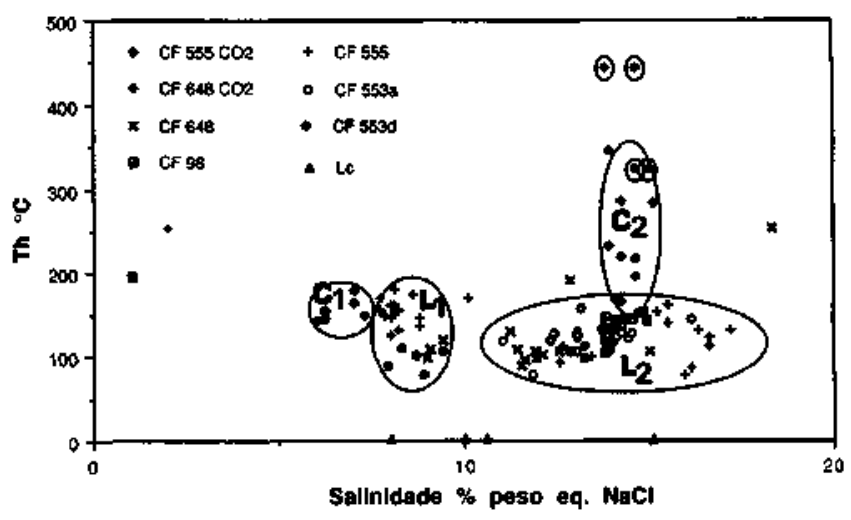

Figura 8 - Diagrama Th $x$ salinidade obtido nas mesmas inclusões. Cada tipo descrito $\left(C_{1}, C_{2}, L_{1}\right.$ e $\left.L_{2}\right)$ ocupa um campo próprio. As inclusões marcadas com um pequeno círculo apresentaram evidencias de vazamento (leakage) durante o aquecimento

Figure 8 - Th $\mathrm{x}$ salinity diagram, data from the same inclusions. Each described type $\left(\mathrm{C}_{1}, \mathrm{C}_{2}, \mathrm{~L}_{1}\right.$ and $\left.\mathrm{L}_{2}\right)$ occupies his own domain. The encircled inclusion has shown leakage evidences during heating

A dispersão dos dados microtermométricos provocada pelos fenômenos de vazamento e estrangulamento, especialmente quando não-identificados, podem dificultar sobremaneira a sua interpretação, como é possível verificar na figura 9. Mas isto não significa que todos indistintamente devam ser abandonados; se as medidas produzem resultados bem agrupados, forçosamente estes resultados possuem algum significado, que precisa ser conhecido (Weisbrod 1984).

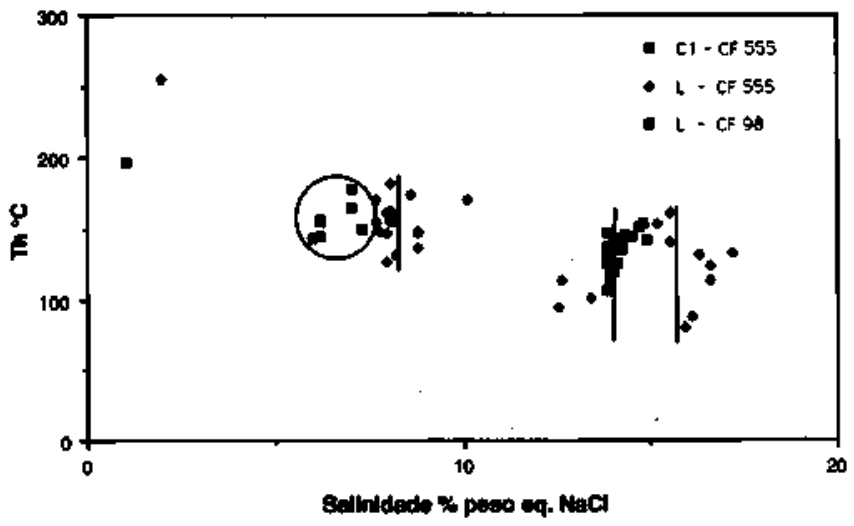

Figura 9-Diagrama Th $x$ salinidade (amostras CF 555 e CF 98, Córrego da água Fria). As tendências verticais representam estrangulamento. A dispersão dos dados impossibilita a interpretação. Entretanto, os valores de salinidade correspondem aos tipos $L_{1}$ e $L_{2}$

Figure 9 - Th x salinity diagram (CF 555 and CF 98 samples from Córrego da Água Fria). The vertical trends are necking down evidences; the scattering data troubled the interpretation, althought the salinity data show a clearly correspondance with the $\mathrm{L}_{1}$ and $\mathrm{L}_{2}$ types

A figura 10 , com os resultados obtidos nas amostras do Morro do Ouro e mina do Periquito, apresenta dados razoavelmente bem agrupados para os tipos $\mathrm{L}_{1}, \mathrm{~L}_{2}$ e $\mathrm{C}_{2}$. Na mina do Periquito, mesmo levando em conta a ausência do tipo aquocarbônico, as inclusões do tipo $\mathrm{L}_{1}$ e $\mathrm{L}_{2}$ superimpõe-se e reforçam os resultados obtidos no Morro do Ouro.

A tendência vertical das inclusões tipo $\mathrm{C}_{2}$, observada na figura 10, pode resultar de três fatores principais: 1. alterações pós-formacionais: estrangulamento, vazamento ou deformação permanente (stretching). Evitou-se utilizar dados provenientes de inclusões onde são evidentes os indícios de alterações pós- 
formacionais; 2. diminuição da pressão, temperatura ou ambos ao mesmo tempo; 3. aumento de temperatura devido à elevação do gradiente térmico (intrusão ígnea). Foi construído, também, o diagrama $\mathrm{ThCO}_{2}$ x salinidade (Fig. 11), o qual permite o uso de um número maior de dados e que reforçam a tendência observada para as inclusões tipo $\mathrm{C}_{2}$ na figura 10 . Estes dados permitem suspeitar que o fluido aquo-carbônico $\mathrm{C}_{2}$ tenha sofrido uma diminuição de temperatura e/ou pressão sem variar significativamente sua salinidade até atingir as condições de temperatura e salinidade do fluido $\mathrm{L}_{2}$. Convém lembrar que os tipos de inclusões $\mathrm{C}_{2}$ e $\mathrm{L}$ são encontrados lado a lado em alinhamentos grosseiros na amostra do Morro do Ouro (CF 648, Fig. 2).

Os fluidos $\mathrm{L}_{2}$ (quente e salino) e $\mathrm{L}_{1}$ (relativamente mais frio e menos salino), cujas inclusões ocorrem sistematicamente associadas em alinhamentos e agrupamentos grosseiros nas três ocorrências estudadas, apresentam uma correlação positiva dos dados de Th e salinidade. Esta tendência pode ser interpretada de acordo com Ramboz (1980) e Shepherd et al. (1985) como apresentando uma mistura; isto é, diluição de dois fluidos (Fig. 10).

Qual a relação do fluido aquo-carbônico precoce (inclusões tipo $\mathrm{C}_{2}$ ) com a mistura de fluidos aquosos tardios (inclusões tipos $\left.\mathrm{L}_{1}+\mathrm{L}_{2}\right)$ ? A constatação de que estes dois tipos de inclusões ocorrem associados em grupos e alinhamentos grosseiros na amostra do Morro do Ouro poderia ser indício de sua cogeneticidade. Assim sendo, em linhas gerais, é possível sugerir a ocorrência de um fluido aquo-carbônico salino em resfriamento que sofre uma mistura mecânica com fluidos aquosos salinos mais frios. A existência de inclusões carbônicas com proporções gradualmente variáveis de $\mathrm{CO}_{2}$ (de 22,4 a $5,9 \%$ peso de $\mathrm{CO}_{2}$ ) e de inclusões aquosas com fraca presença de $\mathrm{CO}_{2}$ apenas detectável pela espectrometria Raman (tipo Lc), poderia constituir mais um indício desta mistura gradual. Esta variação gradual é também sugerida pelos espectros Raman das inclusões fluidas tipos $C_{1}$ e $C_{2}$. Neste caso, o fluido carbônico $\mathrm{C}_{1}$, mais frio, menos salino, menos denso e com proporções de $\mathrm{CO}_{2}$ (de 8,9 a $4,2 \%$ peso $\mathrm{CO}_{2}$ ) menores ou equivalentes às mais fracas do tipo $\mathrm{C}_{2}$, pode ser considerado como resultado da mistura do fluido aquo-carbônico original com os fluidos aquosos tardios.

Por outro lado, parece razoável pensar que as variações das proporções de $\mathrm{CO}_{2}$ possam ser explicadas pelo estrangulamento e/ou avaliações imprecisas do volume da fase $\mathrm{CO}_{2}$. Porém, os dados da espectrometria molar Raman, especialmente a existência do tipo Lc constituem um forte indício a favor da ocorrência de uma mistura de fluidos aquosos (tipo L) com fluidos carbônicos (tipo C). Se esta mistura for considerada possível, poderão ser tecidas algumas considerações interessantes sobre a evolução do fluido mineralizante e as condições de transporte e deposição do ouro.

EVOLUÇÃO DO FLUIDO MINERALIZANTE As citadas variações quantitativas da composição química dos fluidos foram determinadas por meio do cálculo da composição das inclusões. Os parâmetros utilizados nestes cálculos foram aqueles obtidos a partir dos dados microtermométricos e interpretados em relação aos dados experimentais do sistema $\mathrm{H}_{2} \mathrm{O}$ $\mathrm{NaCl}$ (Potter 1977, Potter et al. 1978) e do sistema $\mathrm{H}_{2} \mathrm{O}-\mathrm{CO}_{2}$ (Hollister \& Burrus 1976, Swanenberg 1979), cujos resultados estão agrupados nas tabelas 1 e 2 . As composições globais das inclusões aquo-carbônicas $\mathrm{C}_{2}$ e $\mathrm{C}_{1}$ caracterizam uma fase da evolução do sistema hidrotermal, definida pelo aprisionamento sucessivo de inclusões carbônicas cujo teor em água aumenta progressivamente sem incorporar $\mathrm{CH}_{4}$ e outros voláteis $\left(\mathrm{C}_{2}->\mathrm{C}_{1}\right.$, Fig. 12A). Uma tal evolução de composição traduz, sem dúvida, uma diluição progressiva dos fluidos carbônicos dentro de um progresso sem variações notáveis da $\mathrm{fO}_{2}$. Esta diluição está relacionada à introdução dos fluidos L, fenômeno este que se efetuou durante uma evolução termo-

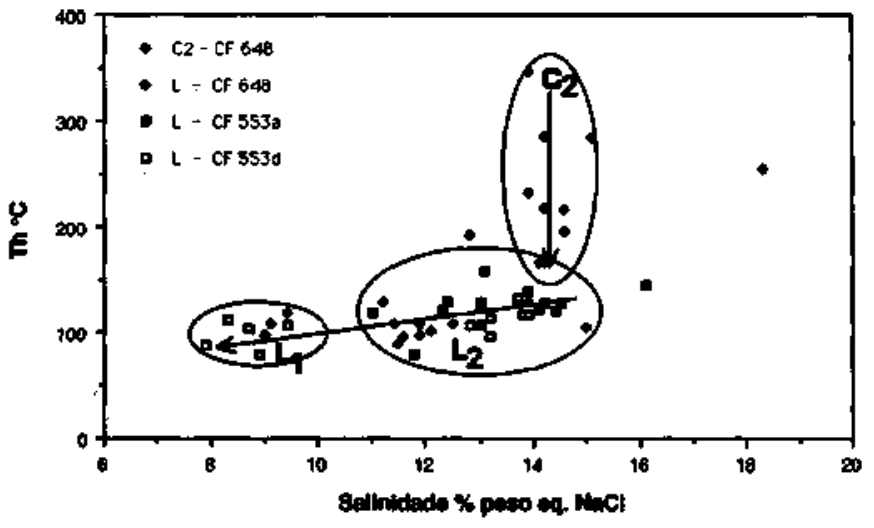

Figura 10 - Superposição dos dados Th x salinidade da Mina do Periquito (CF 553a, d) e do Morro do Ouro CF 648)

Figure 10 -Th x salinity diagram of the Periquito's mine (CF $553 \mathrm{a}, \mathrm{d}$ ) and of

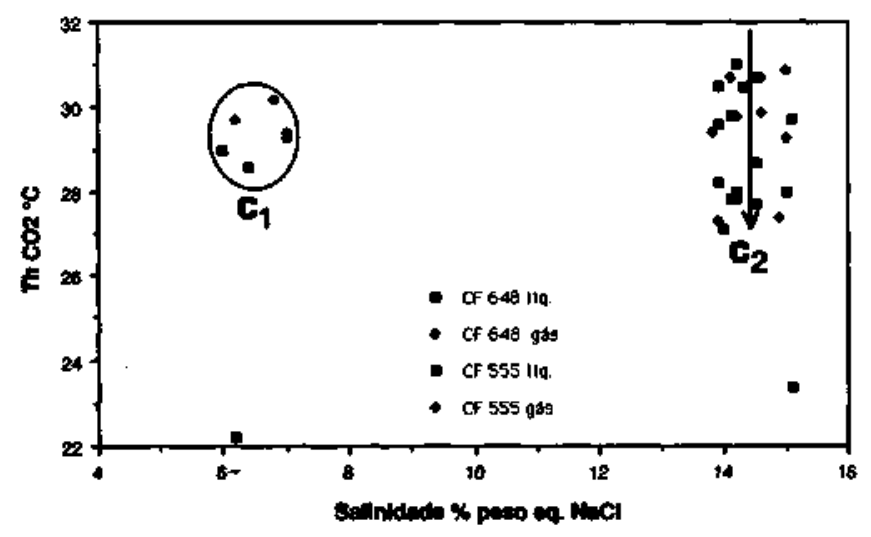

Morro do Ouro (CF 648)

Figura 11 - Diagrama $\mathrm{Th}^{\mathrm{CO}} \mathrm{CO}_{2}$ salinidade das amostras $\mathrm{CF}$ 648 (Morro do Ouro) e CF 555 (Córrego da Água Fria), liq. homogeneização na fase líquida, gás. homogeneização na fase vapor

Figure $11-\mathrm{CO}_{2}$ homogenization temperature $\mathrm{x}$ salinity diagram (CF 648 Morro do Ouro and CF 555 - Córrego da Água Fria), liq. liquid phase homogenization, gas. vapor phase homogenization

barométrica regular caracterizada pelo aprisionamento de fluidos subcríticos. As condições de pressão e temperatura deste processo devem ser estabelecidas próximo às condições críticas que permitem a mistura dos fluidos $\mathrm{C}_{2} \mathrm{M}$ (máximo) e o fluido $\mathrm{L}_{2}$, isto é, por volta de $350^{\circ} \mathrm{C}$ e com uma pressão de 2,0 a 2,5 kbar (Fig. 12B). As condições da evolução $\mathrm{C}_{2} \rightarrow \mathrm{C}_{1}$ desenvolveram-se com a diminuição da salinidade (de 15 a $6 \%$ eq. peso $\mathrm{NaCl}$ ) e também de temperatura e pressão com o aprisionamento do fluido $\mathrm{C}_{1} \mathrm{~m}$ (mínimo) em aproximadamente $150^{\circ} \mathrm{C} 31,8$ kbar de pressão.

A presença das inclusões tipo Lc comprova esta mistura mecânica de fluidos com uma variação notável das salinidades distribuídas entre 8 e $15 \%$ eq. peso $\mathrm{NaCl}$. A figura $12 \mathrm{~A}$ ilustra esta evolução de composição dos fluidos $\mathrm{C}_{2} \mathrm{M}->\mathrm{C}_{1} \mathrm{~m}$ e Lc.

As inclusões fluidas dos filões de quartzo auríferos de Costa Sena registram uma evolução termobarométrica regular caracterizada pela circulação de fluidos aquo-carbônicos precoces, ricos em $\mathrm{CO}_{2}$ e de salinidade média a forte, para temperaturas de $400-450^{\circ} \mathrm{C}$ e pressões de cerca de 3 kbar (estágio hipotermal do sistema hidrotermal). Estes fluidos aquo-carbônicos precoces exibem uma evolução físico-química caracterizada por um aumento do teor em água do fluido e um abaixamento do teor em $\mathrm{CO}_{2}$ durante um decréscimo regular das condições termobarométricas. Esta evolução pode ser interpretada como uma diluição progressiva das inclusões aquo-carbônicas em condi- 


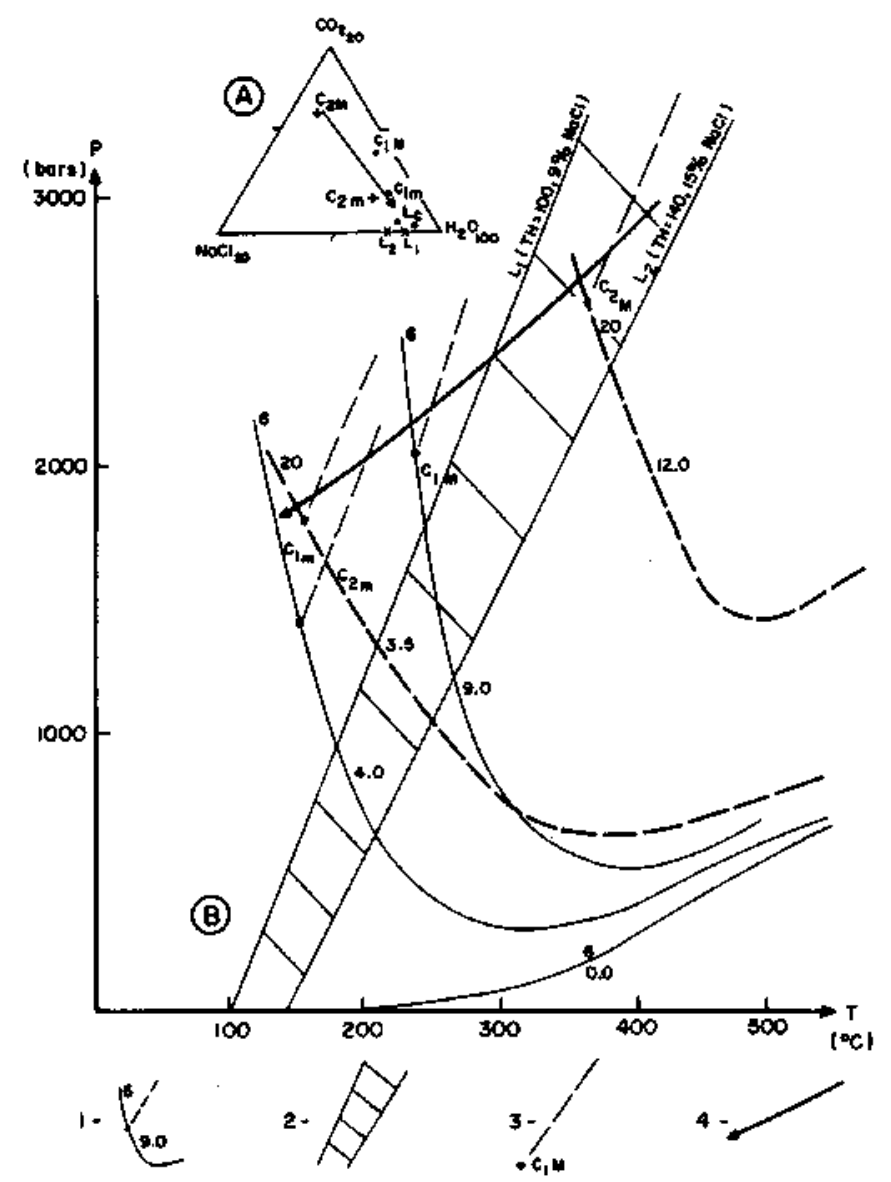

Figura 12 - Reconstrução das condições $P-T-X$ da evolução dos fluidos aquo-carbônicos (tipo $C_{2}, C_{1}$ ) e aquosas $\left(L_{2}, L_{1}\right)$ $\boldsymbol{A}$. Evolução da composição química dos fluidos no diagrama triangular $\mathrm{CO}_{2}-\mathrm{H}_{2} \mathrm{O}-\mathrm{NaCl}$. Os dados das inclusões $\mathrm{C}_{2} \mathrm{M}$ ( $C_{2}$ máximo); $C_{2} M$ ( $C_{2}$ mínimo), $C_{1} M, C_{1} m ; L_{1}, L_{2}$ e Lc correspondem àqueles das tabelas 1 e 2. A flecha mostra a evolução da composição dos fluidos com o desaparecimento do $\mathrm{CO}_{2}$ (fluidos $L c$, $L_{2}$ e $L_{1}$ ). B. Evolução termobarométrica dos fluidos no diagrama $P$ x T. 1. curva crítica do sistema $\mathrm{H}_{2} \mathrm{O}-\mathrm{CO}_{2}-\mathrm{NaCl}$ para uma composição de $6 \%$ eq. peso $\mathrm{NaCl}$; 9,0 moles \% do $\mathrm{CO}_{2}$; 2. isócoras dos fluidos $\mathrm{L}_{2}$ e $\mathrm{L}_{1}$, com o domínio de possível circulação destes fluidos; 3. isócora para o fluido CM da tabela 1; 4. provável evolução $P-T$ do fluido aquo-carbônico

Figure 12 - Reconstruction of aqueous ( $\mathrm{L}_{2}, \mathrm{~L}_{1}$ types) and aquo-carbonic fluids $\left(\mathrm{C}_{2}, \mathrm{C}_{1}\right.$ types $) \mathrm{P}-\mathrm{T}-\mathrm{X}$ evolution. A. Evolution of the fluids chemical composition in the $\mathrm{CO}_{2}-\mathrm{H}_{2} \mathrm{O}-\mathrm{NaCl}$ triangular diagram. The $\mathrm{C}_{2} \mathrm{M}\left(\mathrm{M}=\right.$ maximum), $\mathrm{C}_{2} \mathrm{~m}$ $\left(\mathrm{m}=\right.$ minimum), $\mathrm{C}_{2} \mathrm{M}, \mathrm{C}_{1} \mathrm{~m} ; \mathrm{L}_{1}, \mathrm{~L}_{2}$ and $\mathrm{Lc}$ inclusion data are in the tables 1 and 2. The arrow shows the fluids composition evolution with $\mathrm{CO}_{2}$ proportions decrease ( $L c, L_{2}$ and $L_{1}$ fluids). B. Thermobarometric fluids evolution in the $\mathrm{P} x \mathrm{~T}$ diagram. 1. critical curve of the system $\left.\mathrm{H}_{2} \mathrm{O}\right)-\mathrm{CO}_{2}-\mathrm{NaCl}$ to a composition of 6 weight $\%$ eq. $\mathrm{NaCl} ; 9.0 \mathrm{~mol} \% \mathrm{CO}_{2} ; \mathbf{2} . \mathrm{L}_{2}$ and $\mathrm{L}_{1}$ fluids isochores, 3 . $\mathrm{C}_{1} \mathrm{M}$ fluid isochore; 4 . probable $\mathrm{P}-\mathrm{T}$ evolution of the aquo-carbonic fluid

ções oxidantes. Fluidos aquosos de salinidade fraca são aprisonados durante os estágios mais tardios da evolução (estágio mesotermal do sistema hidrotermal).

CONDIÇÕES DE TRANSPORTE E DEPOSIÇÃO DO

OURO $\mathrm{O}$ transporte do ouro pode ser relacionado ao fluido aquo-carbônico, e o processo de diluição progressiva assinalado foi provavelmente favorável à sua precipitação no estado nativo. Estes processos de diluição implicam em variações das composições dos fluidos (Ramboz 1980, Giuliani 1984), assim como o aumento do $\mathrm{pH}$, que são susceptíveis

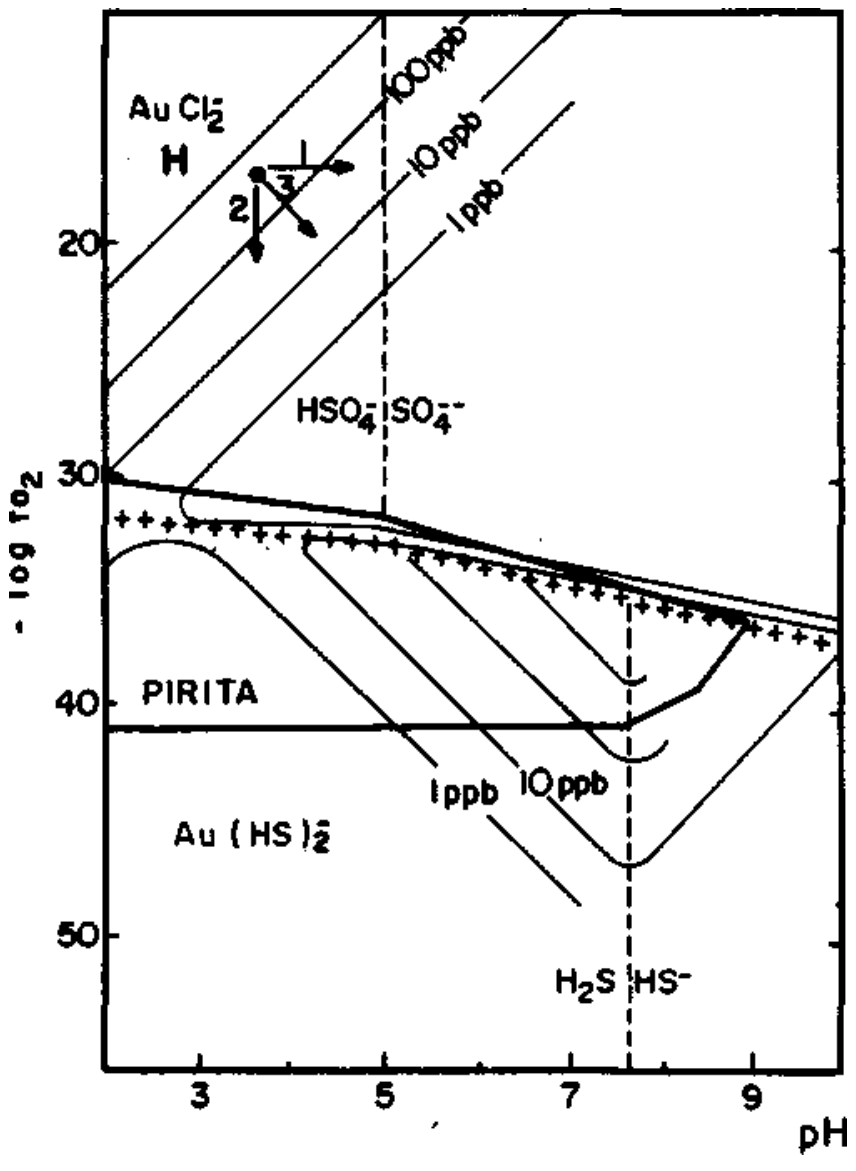

Figura 13 - Diagrama log $\mathrm{fO}_{2}$ - pH apresentando as curvas de isolubilidade do ouro na forma $\mathrm{AuCl}^{2-}$ e $\mathrm{Au}(\mathrm{HS})^{2-}$ a $\boldsymbol{T}=250^{\circ} \mathrm{C}, \sum s=0,02 \mu$ (Seward \& Barnes 1987 in Touray 1987); H. campo de estabilidade da hematita; os traços fortes delimitam o campo de existência da pirita Figure $13-\mathrm{fO}_{2} \times \mathrm{pH}$ diagram showing the $\left(\mathrm{AuCl}^{2-}\right.$ and $\left.\mathrm{Au}(\mathrm{HS})^{2-}\right)$ gold isolubility curves at $\mathbf{T}=250^{\circ} \mathrm{C}, \sum \mathrm{s}=0,02 \mathrm{n}$ (Seward \& Barnes 1987 in Touray 1987); H. stability domain of hematite, the strong lines shown the pyrite domain

de diminuir a solubilidade dos elementos, como o ouro (Touray 1987 in Touray, J-C), especialmente na faixa de temperatura determinada para este estudo (entre 150 e $350^{\circ} \mathrm{C}$ ). Os dados sobre a solubilidade do ouro nos diagramas $\log \mathrm{fO}_{2}-\mathrm{pH}$ (Seward \& Barnes 1987), com as espécies complexantes $\mathrm{AuCl}_{2} \mathrm{e}$ $\mathrm{Au}(\mathrm{HS})_{2}$, e nos intervalos de temperatura do estudo mostram (Fig. 13): a total ausência da pirita na paragênese e a presença constante de fato este que deve ser correlacionado também com a ausência de $\mathrm{CH}_{4}$ e outros voláteis como $\mathrm{H}_{2} \mathrm{~S}$ e $\mathrm{N}_{2}$ nos fluidos. Estas constatações implicam em condições de fugacidade de oxigênio elevadas que correspondem, na figura 13, ao campo de estabilidade da hematita (domínio H-). Neste domínio, onde predominam $\mathrm{HSO}_{4}^{-} \mathrm{e} \mathrm{SO}_{4}^{2-} \mathrm{O}$ ouro é solúvel sob a forma de $\mathrm{AuCl}_{2}$. Os mecanismos de precipitação possíveis do ouro serão: 1. uma elevação do $\mathrm{pH}, 2$. uma diminuição da $\mathrm{fO}_{2}$, ou 3. ambos (percursos 1, 2 e 3 da figura 13). A mistura dos fluidos se desenvolveu de acordo com uma evolução termobarométrica regular com diminuição de $\mathrm{P}$ e $\mathrm{T}$, sem variação da composição química do componente carbônico $\left(\mathrm{CO}_{2}\right.$ puro). Portanto, esta evolução foi realizada a $\mathrm{fO}_{2}$ constante; e, neste caso, a precipitação do ouro resultou do aumento do pH da solução (trend I, Fig. 13), fenômeno este favorecido pelo processo de diluição do fluido carbônico inicial. 
CONCLUSÕES Apesar das dúvidas levantadas pela ocorrência de alterações pós-formacionais e da cronologia dos diversos tipos de inclusões não ser absolutamente clara, ocorrem para todas as amostras estudadas: (1) inclusões fluidas aquo-carbônicas - correspondem às inclusões fluidas precoces cuja temperatura de homogeneização situa-se entre +150 e $+300^{\circ} \mathrm{C}$ e as salinidades entre 6 e $14 \%$ eq. peso $\mathrm{NaCl}$. Tratamse de fluidos com $\mathrm{CO}_{2}$ puro e possíveis traços de $\mathrm{CH}_{4}$; (2) aquosas - são inclusões aquosas tardias, bifásicas em temperatura ambiente, com Th entre 70 e $200^{\circ} \mathrm{C}$, e salinidades variáveis, entre 8 e $13 \%$ eq. peso $\mathrm{NaCl}$.

A análise dos dados microtermométricos e Raman relativos às inclusões fluidas dos veios de quartzo auríferos de Costa Sena permitiu a caracterização de alguns parâmetros físicoquímicos dos fluidos responsáveis pelo transporte e deposição do ouro. As proporções gradualmente variáveis de $\mathrm{CO}_{2}$ e a existência do tipo Lc verificada pela espectrometria Raman permitem supor uma evolução do sistema hidrotermal caracterizada pelo aprisionamento sucessivo de inclusões fluidas aquo-carbônicas cujo teor em água aumenta progressivamente. Este processo característico de um fenômeno de diluição se desenvolveu em condições de fO2 constante, durante diminuição de salinidade, temperatura e pressão.

A ausência de pinta e a presença de hematita implicam em alta $\mathrm{fO}_{2}$, que é o domínio de predominância de $\mathrm{HSO}_{4}^{-}$e $\mathrm{SO}_{4}{ }^{2}$-, no qual o ouro é solúvel sob a forma de $\mathrm{AuC}_{2}$. Nas condições de fugacidade de oxigênio constante é mais provável supor que o ouro tenha se precipitado devido a um aumento do $\mathrm{pH}$ da solução, processo este favorecido pela diluição do fluido carbônico original.

Agradecimentos Este trabalho foi possível graças ao apoio do $\mathrm{CNPq}$ e do convênio CAPES/COFECUB mediante concessão de bolsa, e da infra-estrutura fornecida pela Universidade de Brasília e CNRS - Orleans, França, especialmente na pessoa do Dr. Ph. Rossi. Agradecemos, também, as sugestões do Dr. J-C. Touray.

\section{REFERÊNCIAS BIBLIOGRÁFICAS}

BOZZO, A.T.; CHIEN, J.R.; BARDUHN, A.J. 1973. The properties of hydrates of chlorine and carbon dioxide. In: INTER. SYMP FRESH WATER FROM THE SEA, 4. 1973. Proceedings... v. 3, p. 437-451.

COLLINS, P.F.L. 1979. Gas hydrates in $\mathrm{CO}_{2}$-bearing fluid inclusions and the use of freezing data for estimation of salinity. Econ. Geol. (6): $1435-1444$.

DELHAYE, M.C. \& DHAMELICOURT, P. 1975. Raman microprobe and microscope with laser excition. J. Raman Spectros., 3:33.

FUZIKAWA, K. 1985. Inclusões fluidas: métodos usuais de estudo e aplicações. In: Contribuições à Geologia e à Petrologia. Belo Horizonte, SBG/ NMG. p. 29-44.

GIULIANI, G. 1984. Les concentrations filoniennes à tungstène-étain du massif grantifique des Zaër (Maroc Central): mineralisations et phases fluides associées. Mineral. Deposita, 19(2):193-201.

HOLLISTER, L.S. \& BURRUS, R.C. 1976. Phase equilibria in fluid inclusions from the Khtada lake metamorphic complex. Geochim. Cosmochitn. Acta, 40(2): 163-175.

INDA, H.A.C.; SCHORSCHER, H.D.; DARDENNE, M.A.; SCHOBBENHAUS, C; HARALYI, N.L.E.; BRANCO, P.C.A.; R AM ALHO, R. 1984. O Cráton do São Francisco e a faixa de dobramentos Aracuaí. In: SCHOBBENHAUS C.: CAMPOS, D.A

DERZE, GR,. ASMUS, H.E. (coord.). Geologia do Brasil.' Rio de Janei-

ro, DNPM. p. 193-248. (Capítulo 5).

PFLUG, R. \& CARVALHO, R.T. 1964. A Evolução Estrutural da Região de Gouveia, Serra do Espinhaço, M.G. Rio de Janeiro, DNPM/DGM. (Boletim 213)

POTTER, R.W. 1977. Pressure corrections for fluid inclusions homogenization temperatures based on the volumetric properties of the system $\mathrm{NaCl}-\mathrm{H}_{2} \mathrm{O}$. J. Res. U.S. Geol. Survey, 5(5):603-607.
POTTER, R.W.; CLYNNE, M.A.; BROWN, D.L. 1978. Freezing point depression of aquous sodium chloride solutions. Econ. Geol., 73(2):284-285.

POTY, B.; LEROY, J.; JACHIMOWICZ, L. 1976. Un nouvel appareil pour la mesure des temperatures sous le microscope: 1'installation thermométrique Chaixmeca. Bull. Soc. Fr. Miner., 99(2-3): 182-186.

RAMBOZ, C. 1980. Géochimie et Etude des Phases Fluides de Gisements et Indices d'Etain-Tungstene du Sud du Massif Central (France). Nancy. 278 p. (These $3^{\text {ème }}$ cycle, INPL).

ROSASCO, G.J. \& SIMMONS, J.H. 1974. Investigation of gas content of inclusions by Raman scattering spectroscopy. Am. Ceram. Soc. Bull., 53(9): $626-630$.

SCHÖLL, W.U. 1980. Estratigrafia, sedimentologia com paleogeografia na região de Diamantina (Serra da Espinhço, MG, Brasil). Münstersche Forsch. Geol. Paläontol, 51:223-40.

SHEPHERD, T.S.; RANKIN, A.H.; ALDERTON, D.H.M. 1985. A Practical Guide to Fluid Inclusion Studies. London, Ed. Blackie. 239 p.

SWANENBERG, H.E.C. 1979. Phase equilibria in carbonic systems and their application to freezing studies of fluid inclusions. Contrib. Mineral. Petrol. 68:303-306.

TOURAY, J-C. 1987. Transport et depot de 1'or dans les fluides de Ia crôute continentale, 1'apport des etudes d'inclusions fluides. Chron. Rech. Min., 55(488):43-53.

WEISBROD, A. 1984. Utilisation des inclusions fluides en geothermobarorométrie et Barometric Géologiques. Soc. Franç. Min. Cristal., 2:413-459.

MANUSCRITO A690

Recebido em 26 de janeiro de 1991 Revisão do autor em 6 de fevereiro de 1992 Revisão aceita em 26 de fevereiro de 1992 